\title{
Effect of Storage Temperature on the Dephosphorylation of Nucleotides in Fish Muscle
}

\author{
Kazuko Tomioka, ${ }^{* 1}$ Taeko Kuragano, ${ }^{* 2}$ Hiromi Yamamoto, ${ }^{* 3}$ \\ and Kinji Endo*s
}

(Accepted July 17, 1986)

\begin{abstract}
At a temperature range from $-5^{\circ} \mathrm{C}$ to $20^{\circ} \mathrm{C}$, the Arrhenius plot of the dephosphorylation of nucleotides in cod muscle exhibited one break point at around $-2^{\circ} \mathrm{C}$, the plot of carp muscle at about $5^{\circ} \mathrm{C}$, but the plot of yellowtail exhibited two break points at around $-2^{\circ} \mathrm{C}$ and $10^{\circ} \mathrm{C}$. These break points at around $-2^{\circ} \mathrm{C}$ disappeared on the addition of glycerin as an antifreeze. The Arrhenius plots of microsomal $5^{\prime}$-nucleotidase of carp and yellowtail exhibited one break point at $5^{\circ} \mathrm{C}$ and $10^{\circ} \mathrm{C}$ respectively, but the plot of cod showed no break point, in the presence of glycerin. The $\mathrm{Km}$ of microsomal 5 -nucleotidase of carp and yellowtail for IMP markedly increased with descending temperature below the break point. The break point of microsomal 5 'nucleotidase disappeared on the treatment with a surfactant. Therefore, the assumption made is, that the change in kinetics of dephosphorylation of nucleotides at around $-2{ }^{\circ} \mathrm{C}$ may be accounted for by the phase change of water in fish muscle, and the change at the temperature above freezing point may be accounted for by the lipid phase separation in membranes containing 5 -nucleotidase at the definite temperature which is specific to the species of fish.
\end{abstract}

There have been many reports dealing with the degradative change of nucleotides in post-mortem muscle of fish with respect to the quality change of fish, e.g. the K-value, ${ }^{1)}$ the percentage of dephosphorylation products to total nucleotides in fish muscle, being generally considered to be one of the most reliable index for the quality or the freshness of fish. ${ }^{2-5\rangle}$ Through kinetic studies ${ }^{6-3\rangle}$ on the dephosphorylation of nucleotide in muscle of stored fish, it has became clear that rate constants of freshness-lowering of some species of fish followed Arrhenius's function in such temperature range above their freezing points, as -1$20^{\circ} \mathrm{C}^{8)}$ or $0-25^{\circ} \mathrm{C}^{8)}$

We have recently observed, however, that the Arrhenius plot for carp muscle exhibited a break point at $5-6^{\circ} \mathrm{C}$. Then, it is reasonable to suppose that the kinetics of freshness-lowering of fish judged by the dephosphorylation of nucleotides may depend on the species of fish. From a practical point of view, it is of interest to compare the rate of freshness-lowering among different fishes in the temperature range of chilling. It is important to investigate the reason why the kinetics differs from fish to fish. In the present work, the tem- perature dependence of the dephosphorylation of nucleotides in muscle of some different species of fish is kinetically compared with that of microsomal IMP-degrading activity, and factors which control the IMP-degradation by $5^{\prime}$-nucleotidase $\left(S^{\prime}-N\right.$ tase) in fish muscle under chilling is discussed.

\section{Materials and Methods}

\section{Materials}

The fresh dorsal muscles of the following fish were used. Carp Cyprinus carpio $(1.1 \mathrm{~kg}$ in body weight) was obtained alive from a commercial supplier. Frozen cod Gadus macrocephalus (2.4 $\mathrm{kg}$ ) and fresh yellowtail Seriola quinqueradiate $(1.6 \mathrm{~kg})$ were obtained at a local retail shop.

These muscles were chopped into a few pieces, wrapped with a plastic film and stored at $-5,0,5$, 10,15 or $20^{\circ} \mathrm{C}$. These storage temperatures were controlled by water bathes within $\pm 0.2^{\circ} \mathrm{C}$.

\section{Estimation of $H x R$ and $H x$}

A part of the stored muscle was homogenized with $5 \%$ perchloric acid. An aliquot of the filtrate of the homogenate was neutralized with

*1 Nara University of Education, Nara 630, Japan (雷岡和子：奈良教育大学)

*2 Konan Women's Junior College, 6-2-23, Morikita, Higashinada, Kobe 658, Japan (倉贺野妙子：翈南女 子稫期大学).

*3 Faculty of Home Economics, Nara Women's University, Nara 630, Japan (山本裕美, 遠藤金次: 奈良女 子大学家政学部). 


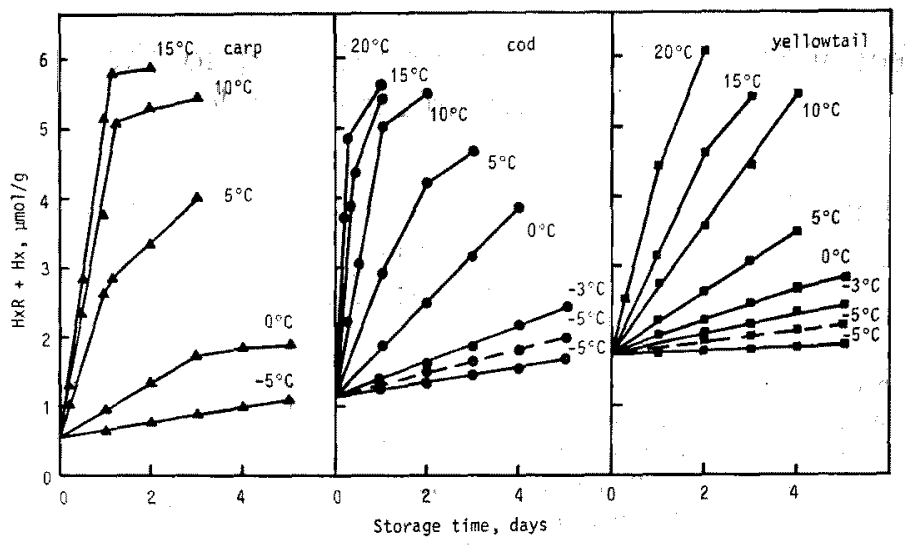

Fig. 1. The dephosphorylation of nucleotides in fish muscle during storage at various temperatures.

Solid line: inosine (HxR) and hypoxanthine $(\mathrm{Hx})$ in the muscle of stored fish in the absence of glycerin.

Broken line: these in the presence of glycerin at temperature $-5^{\circ} \mathrm{C}$.

$\mathrm{KOH}$ and then filtered. The dephosphorylation products of nucleotides, inosine (HxR) and hypoxanthine $(\mathrm{Hx})$, were determined by HPLC using a Hitachi gel $\$ 3013-\mathrm{N}$ column and a gradient elution with phosphate buffer (from $0.06 \mathrm{M}$ to $0.3 \mathrm{M}$ ) in $6 \%$ acetonitril.

\section{Preparation of the Microsomal Fraction}

The ordinary muscle was homogenized with 4 volumes of ice-cold $0.25 \mathrm{M}$ sucrose in a Waring blendor (Nissei AH-11) at the top speed for 30 sec. The fractionation of a microsomal fraction by the differential centrifugation was carried out by the method of Makinodan et al. ${ }^{02}$ After the centrifugation of the homogenate at $27,000 \times \mathrm{g}$ for $30 \mathrm{~min}$, the supernatant was centrifuged again at $123,400 \times \mathrm{g}$ for $90 \mathrm{~min}$. The pellet thus obtained was used as the microsomal fraction.

Treatment of the Microsomal Fraction with a Surfactant

After the addition of Emulgen 109P(polyoxyethylene lauryl alcohol ether, Kao Soap Co.) at the final concentration of $1 \%$, the microsomal fraction was dissolved by stirring at $4^{\circ} \mathrm{C}$ for $60 \mathrm{~min}$.

\section{Assay of Enzyme Activity}

5 -Ntase activity was assayed by the method previously reported, ${ }^{10)}$ using $5 \mathrm{mM}$ IMP as substrate.

\section{Results and Discussion}

Effect of Temperature on the Dephosphorylation of Nucleotides

The effect of the storage temperature on the dephosphorylation of nucleotides for carp, cod and yellowtail during storage at the temperature between $-5^{\circ} \mathrm{C}$ and $20^{\circ} \mathrm{C}$ was examined. The results are presented in Fig. 1. It is noteworthy that, at $-5^{\circ} \mathrm{C}$ where water in muscle partially froze, the dephosphorylation of nucleotides was accelerated by the addition of glycerin as and antifreeze in cod and yellowtail, but not in carp. It was obvious that $\mathrm{HxR}$ and $\mathrm{Hx}$ linearly increased with increasing the storage period at the early stage of storage. Therefore, the dephosphorylation of nucleotides in these fish muscles at the early stage could be regarded as a zero-order reaction. The consideration should be supported by the fact that the concentration of IMP in fresh fish muscle was much higher than the $\mathrm{Km}$-value of muscle microsomal $5^{\prime}$-Ntase for IMP. Then, the rate constants of dephosphorylation of nucleotides in these fish muscles should be obtained by the slopes of lines given in Fig. 1 at the early stage of the storage.

The logarithms of the rate constants of dephosphorylation of nucleotides, read from the slopes of lines in Fig. 1, were plotted against the reciprocal of absolute temperature as shown in Fig. 2. The Arrhenius plot of dephosphorylation of nucleotides in carp muscle showed one break point at about $5^{\circ} \mathrm{C}$, and the activation energies 


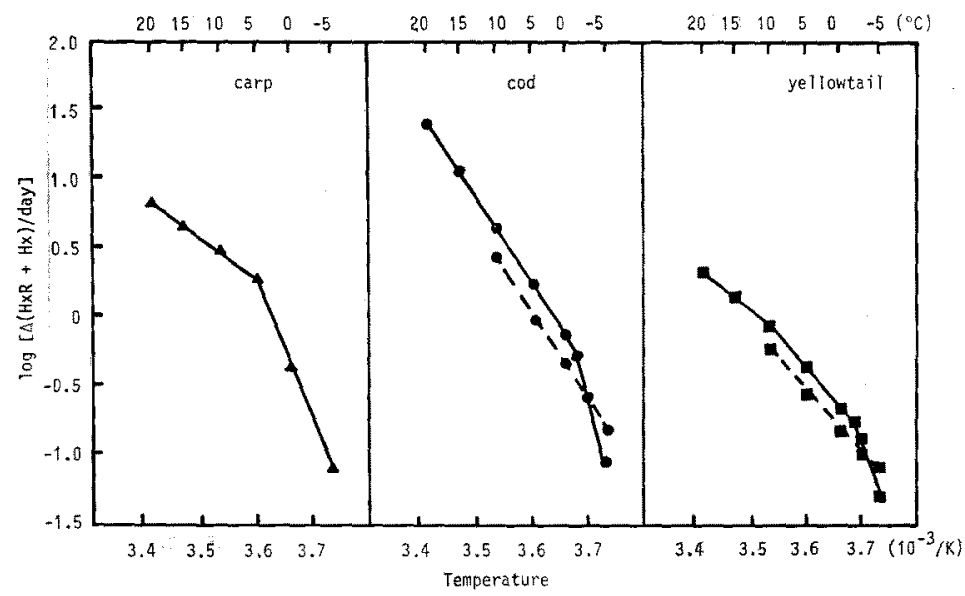

Fig. 2. Arrhenius plots of the dephosphorylation of nucleotides in fish muscle. Broken line: plots in the presence of glycerin.

were calculated to be $14 \mathrm{kcal} / \mathrm{mol}$ at the temperature above $5^{\circ} \mathrm{C}$ and $46 \mathrm{kcal} / \mathrm{mol}$ between $-5^{\circ} \mathrm{C}$ and $5^{\circ} \mathrm{C}$. The plot for yellowtail muscle showed two break points at about $10^{\circ} \mathrm{C}$ and $-2{ }^{\circ} \mathrm{C}$, and the activation energies were calculated to be $14 \mathrm{kcal} /$ mol at the temperature above $10^{\circ} \mathrm{C}, 22 \mathrm{kcal} / \mathrm{mol}$ between $10^{\circ} \mathrm{C}$ and $-2^{\circ} \mathrm{C}$, and $71 \mathrm{kcal} / \mathrm{mol}$ below $-2^{\circ} \mathrm{C}$. In the case of cod muscle, the plot showed one break point at about $-2^{\circ} \mathrm{C}$, and the activation energies were calculated to be $29 \mathrm{kcal} / \mathrm{mol}$ at the temperature above $-2^{\circ} \mathrm{C}$ and $57 \mathrm{kcal} / \mathrm{mol}$ below $-2^{\circ} \mathrm{C}$.

The steep slopes of lines in Fig. 2 at the temperature below $-2{ }^{\circ} \mathrm{C}$, where the activation energies were about $50 \mathrm{kcal} / \mathrm{mol}$ or more, were in common with the Arrhenius plots of changes in K-values reported by Miki and Nishimoto ${ }^{7)}$ who showed one break point on the plots at about $-2{ }^{\circ} \mathrm{C}$ regardless of fish species. On the addition of glycerin as an antifreeze to muscles of cod and yellowtail, the slopes of the same plots at the temperature below $-2^{\circ} \mathrm{C}$ became gentle as shown by broken lines in Fig. 2 , and the break point on the plots at about $-2^{\circ} \mathrm{C}$ disappeared. This fact indicates that the change in the kinetics of dephosphorylation of nucleotides at about $-2{ }^{\circ} \mathrm{C}$ should be caused by the melting of ice or the freezing of water in muscles of major species of fish. In the case of carp muscle, the change in the kinetics of dephosphorylation of nucleotides occurred at about $5^{\circ} \mathrm{C}$ due to the other mechanism which will be later discussed, than the phase-change of water, and the activation energy at the temperature below about $5^{\circ} \mathrm{C}$ amounted to as much as $46 \mathrm{kcal} / \mathrm{mol}$.
This activation energy value was almost the same as those of major species of fish at the temperature below about $-2^{\circ} \mathrm{C}$. This large value may account for the fact that the Arrhenius plot of dephosphorylation of nucleotides in carp muscle did not break at about $-2^{\circ} \mathrm{C}$ where water in the muscle partially froze.

\section{Effect of Temperature on the Activity of Micro- somal 5'-Ntase}

It has been known that the enzyme hydrolyzing IMP, which plays a key role in the dephosphorylation of nucleotides in fish muscle during the storage, is a membrane-bound $5^{\prime}-N_{\text {tase }}{ }^{10)}$ and is mainly contained in the microsomal fraction of fish muscle. ${ }^{11}$ In order to obtain a detailed information on the kinetics of dephosphorylation of nucleotides in fish muscle, the effect of temperature on activities of the microsomal $5^{\prime}-\mathrm{N}$ tase of fish muscles was examined.

On the basis of $5^{\prime}$-Ntase activities of microsomal fractions prepared from fish muscles at the temperature between $-5^{\circ} \mathrm{C}$ and $20^{\circ} \mathrm{C}$ in the presence of glycerin as an antifreeze, the Arrhenius plots were obtained as shown in Fig. 3. The plots of microsomal 5'-Ntase of carp showed one break point at about $5^{\circ} \mathrm{C}$, that of yellowtail at about $10^{\circ} \mathrm{C}$, but that of cod showed no break point. These break points and the activation energies calculated from the slopes of these plots were in good agreement with those of the dephosphorylation of nucleotides in fish muscles in the presence of glycerin shown in Fig. 2. This agreement indicates that the kinetics of dephosphorylation of 


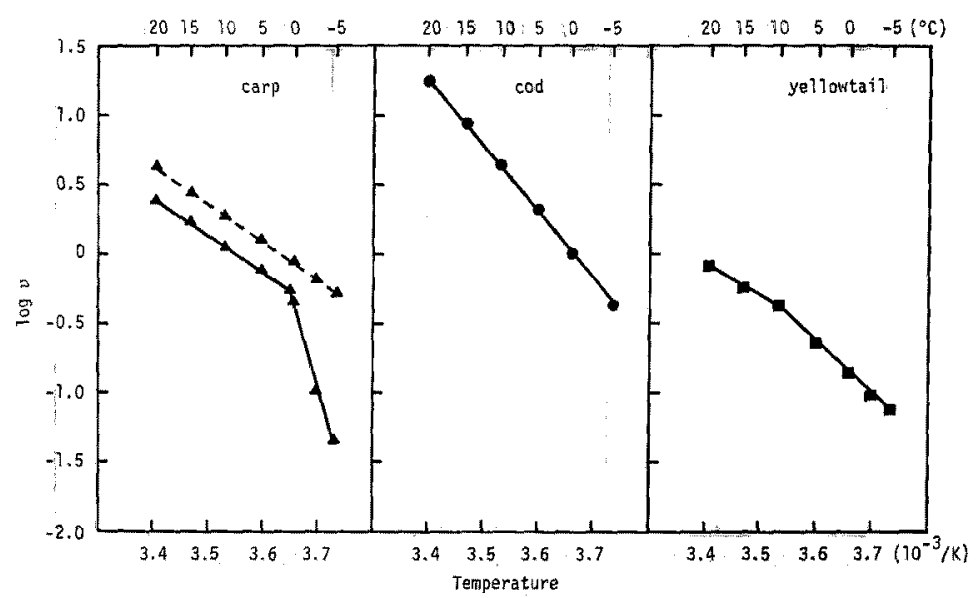

Fig. 3. Arrhenius plots of the activity of microsomal $5^{\prime}$-nucleotidase. Broken line: plots in the presence of a surfactant.

nucleotides in fish muscle should depend on the kinetics of microsomal $5^{\prime}$-Ntase activity.

On the treatment of carp microsomal fraction with Emulgen 109P, a surfactant, as shown in a broken line in Fig. 3, the break point at about $5^{\circ} \mathrm{C}$ disappeared in the Arrhenius plot of microsomal 5'-Ntase activity. The Arrhenius plot of activity of carp muscle $5^{\prime}$-Ntase purified by the previously reported method ${ }^{10)}$ also exhibited no break point at the temperature above $-2{ }^{\circ} \mathrm{C}$, though the experimental data were not shown. On the other hand, it has been demonstrated that the Arrhenius plots of activities of a number of membrane-bound enzymes exhibited break points and the temperatures at which such break points occurred were correlated with that of the lipid phase separations in the membranes. ${ }^{12,13}$ ) It has also been reported that $5^{\prime}$-Ntase in fish muscle was membranebound. $10,14-18)$ Therefore, it is reasonable to suppose that the break shown in the Arrhenius plot of 5'-Ntase activity of muscle microsome at the temperature above the freezing point shown in Fig. 3 should be correlated with the abrupt change in the characteristic of some surfactant-soluble components in the microsome, with which 5 Ntase associates, or with the lipid phase separation in membranes (perhaps plasma membrane) being contained in the microsome at a definite temperature which appears to vary from species to species of fish.

Effect of Temperature on the Kinetic Parameters of Microsomal 5'-Ntase

In order to obtain some information on the

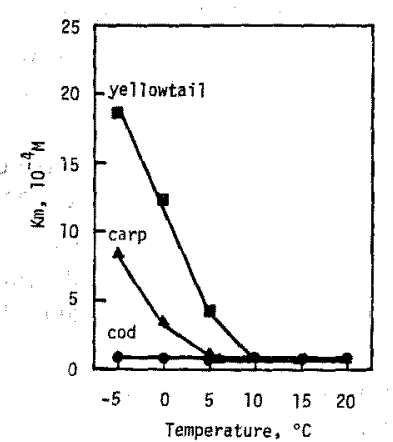

Fig. 4. Effect of temperature on the Michaelis constants $(\mathrm{Km})$ of microsomal $5^{\prime}$-nucleotidase for IMP.

mechanism by which the change in the kinetics of microsomal 5'-Ntase occurred at a definite temperature above freezing point was caused, the Michaelis constants $(\mathrm{Km})$ and the maximum velocities $\left(\mathrm{V}_{\max }\right)$ were determined at various temperatures for the dephosphorylation of IMP by muscle microsomal $5^{\prime}$-Ntase of 3 species of fish. As shown in Fig. 4, the $\mathrm{Km}$ values determined at the temperature above $10^{\circ} \mathrm{C}$ were about $1 \times 10^{-4} \mathrm{M}$ regardless of species of fish. In the case of yellowtail at the temperature below about $10^{\circ} \mathrm{C}$ and in the case of carp at the temperature below about $5^{\circ} \mathrm{C}$, the $\mathrm{Km}$ values of microsomal $5^{\prime}-\mathrm{Ntase}$ for IMP markedly increased with decreasing temperature, but in the case of cod the value never varied with decreasing temperature until $-5^{\circ} \mathrm{C}$. The temperature below which the $\mathrm{Km}$ value increased was in close agreement with the break point shown 
in Fig. 3. On the treatment of microsomal fraction with a surfactant, the increase of $\mathrm{Km}$-value shown in Fig. 4 also disappeared.

The $V_{\max }$ values determined at various temperatures, though data were not shown, were in close agreement with the values of activities shown in Fig. 3, although such agreement is quite acceptable because of that the substrate concentration used in the assay of $5^{\prime}-$ Ntase activities seen in the figure was considerably higher than the $\mathrm{Km}$ values determined. In the cases of carp and yellowtail, at the temperature below the break point seen in Fig. 3, the ratio of $V_{\max }$ value of the surfactanttreated microsomal $5^{\prime}-\mathrm{N}$ tase to that untreated increased with decreasing of temperature.

These results indicate that the abrupt change in kinetic parameters of microsomal $5^{\prime}-N$ tase at the temperature, below a definite temperature which may be specific to the species of fish, should be closely connected with the lipid phase separation in membranes containing $5^{\prime}$-Ntase. The abrupt change in kinetic parameters may be accounted for by the assumption that the changes in the concentration of substrate and reaction products around the active center of microsomal $5^{\prime}$ Ntase may take place with the depression or elevation of those diffusion by the lipid phase separation at microsomal membrane.

As mentioned above, it became clear that the dependence of dephosphorylation of nucleotides in fish muscle on the storage temperature was closely related with that of microsomal $5^{\prime}-$ Ntase, and that the kinetics of dephosphorylation of nucleotides discontinuously changed at around the freezing point of fish muscle and at a definite temperature above the freezing point depending upon the species of fish. The change in the kinetics at around the freezing point, as already indicated by Miki and Nishimoto, ${ }^{7}$ is explained by the phase-change of water in fish muscle.

The change in the kinetics at a definite temperature above the freezing temperature was observed for yellowtail and carp, but not for cod. The temperature at which a break point occurred on the Arrhenius plot of dephosphorylation of nucleotides, depending upon the species of fish, was in close agreement with that at which the Arrhenius plot of microsomal 5 -Ntase broke and that under which the $\mathrm{Km}$-value of microsomal $5^{\prime}$ Ntase remarkably increased. One possible explanation of these observation is that membranebound $5^{\prime}$-Ntase in microsome, which plays a key role in the dephosphorylation of nucleotides in fish muscle, may undergo a conformatory change to a less active form after the lipid phase separation in the membrane at the temperature below a definite temperature which may be specific to the species of fish.

\section{References}

1) T. Saito, K. Arai, and M. Matsuyoshi: Nippon Suisan Gakkaishi, 24, 749-750 (1959).

2) H. Uchiyama, S. Ehira, H. Kobayashi, and W. Shimidu: Nippon Suisan Gakkaishi, 36, 177-187 (1970).

3) H. Uchiyama and S. Ehira: Nippon Suisan Gakkaishi, 36, 977-992 (1970).

4) H. Uchiyama, N. Kato, and S. Ehira: Bull. Tokai Reg. Fish. Res. Lab،, 72, 1-8 (1972).

5) H. Uchiyama, S. Ehira, and N. Kato: in "Sakanano-Hinshitsu" (ed. by the Japanese Society of Scientific Fisheries), Suisangaku Series 4, Koseisha-Koseikaku, Tokyo, 1974, pp. 81-103.

6) J. Nishimoto, R. L. Elomina, and H. Miki: Mem. Fac. Fish, Kagoshima Univ, 30, 405-409 (1981).

7) H. Miki and J. Nishimoto: Nippon Suisan Gakkaishi, 50, 281-285 (1984).

8) A. Hara and F. Uda: Nippon Suisan Gakkaishi, 50, 1745-1756 (1984).

9) Y. Makinodan, N. N. Kyaw, and S. Ikeda: Comp. Biochem. Plysiol., 73B, 785-789 (1982).

10) K. Tomioka and K. Endo: Nippon Suisan Gakkaishi, 50, 1077-1081 (1984).

11) Y. Yamamoto, K. Endo, Y. Kadowaki, and H. Kishida: J. Jpn. Soc. Nutr. Food Sci., 19, 385389 (1967).

12) M. D. Houslay and R. W. Palmer: Biochem. J., 174, 909-919 (1978).

13) M. D. Houslay, J. C. Metcalfe, G. B. Warren, T. R. Hesketh, and G. A. Smith: Biochim. Biophys. Acta, 436, 489-494 (1976).

14) Y. T. Woo and J. F. Manery: Biochim. Biophys. Acta, 397, 144-152 (1975).

15) S. D. Shimmel, C. Kent, R. Bishoff, and P. R. Vageles: Proc. Natl. Acad. Sci. USA, 70, 31953199 (1973).

16) L. W. Hayes, C. A. Goguen, A. L. Stevens, W. W. Magargal, and L. L. Slakey: Proc. Natl. Acad. Sci. USA, 76, 2532-2535 (1979). 